\title{
Effects of Hydrolysed Collagen Associated or Not with Physical Agents on Tissue and Muscle Flaccidity-Firmez Method: Case Study
}

\author{
${ }^{1}$ Federal University of Rio Grande do Norte, Natal, Brazil \\ ${ }^{2}$ University Centre of Rio Grande do Norte (UNIRN), Natal, Brazil \\ ${ }^{3}$ Estácio de Sá University, Natal, Brazil \\ ${ }^{4}$ Potiguar University-UNP, Natal, Brazil \\ ${ }^{5}$ Campinas State University (UNICAMP), Campinas, Brazil \\ ${ }^{6}$ Higher School of Sciences of Santa Casa de Misericórdia, Vitória, Brazil \\ ${ }^{7}$ University of São Judas Tadeu, São Paulo, Brazil \\ ${ }^{8}$ Federal University of Rio de Janeiro, Rio de Janeiro, Brazil \\ ${ }^{9}$ University of Medical Sciences of Minas Gerais, Minas Gerais, Brazil \\ Email: *maia.rafaella20@gmail.com
}

Rafaella Rêgo Maia1*, Patrícia Froes Meyer1,2, Rodrigo Marcel Valentim Da Silva1,3, Eneida De Morais Carreiro², Thaynar Gonzaga Da Silva², Lígia De Oliveira Revorêdo², Stephany Luanna Queiroga Farias ${ }^{4}$, Ciro Dantas Soares ${ }^{5}$, Michelle Cordeiro Sanz ${ }^{6}$, Mariana Adélia Girotto Bussade ${ }^{7}$, José Dos Santos Bussade ${ }^{8}$, Mônica Etrusco Pedrosa9

How to cite this paper: Maia, R.R. Meyer, P.F., Da Silva, R.M.V., De Morais Carreiro, E., Da Silva, T.G., De Oliveira Revorêdo, L., Farias, S.L.Q., Soares, C.D., Sanz, M.C., Bussade, M.A.G., Bussade, J.D.S. and Pedrosa, M.E. (2022) Effects of Hydrolysed Collagen Associated or Not with Physical Agents on Tissue and Muscle Flaccidity-Firmez Method: Case Study. Open Journal of Applied Sciences, 12, 82-98.

https://doi.org/10.4236/ojapps.2022.121007

Received: August 30, 2021

Accepted: January 18, 2022

Published: January 21, 2022

Copyright $\odot 2022$ by author(s) and Scientific Research Publishing Inc. This work is licensed under the Creative Commons Attribution International License (CC BY 4.0).

http://creativecommons.org/licenses/by/4.0/ (c) (i) Open Access

\begin{abstract}
The combination of therapies may be the promising future for the treatment of esthetic alterations more efficiently and in less time, in order to obtain an excellent result. Our objective was to evaluate the effectiveness of hydrolysed collagen associated with radiofrequency and electrostimulation in the treatment of flaccidity in the abdominal and gluteal regions. The sample consisted of 6 women, evaluated through evaluation protocols, questionnaires, dynamometry, ultrasound exams, and histological analysis. The volunteers were distributed into three subgroups: hydrolysed collagen group (G-1), radiofrequency + hydrolysed collagen group (G-2) and radiofrequency + hydrolysed collagen + electrostimulation group (G-3). The ultrasound analysis of the abdominal muscles showed an increase in muscle thickness in all groups, but not significant $(\mathrm{p}>0.05)$. The histological analysis showed an evident increase in type I collagen in groups G-2 and G-3, with proliferating cells (Ki67+). The results of dynamometry showed significant values in different times $(\mathrm{p}<$ 0.05). There was a significant result in the infraumbilical perimetry analysis, when compared between the groups with 30 days $(\mathrm{p}=0.03)$ and with 60 days $(p=0.04)$. All participants rated the treatment positively. The use of com-
\end{abstract}


bined therapies has shown superior results for the treatment of abdominal and gluteal flaccidity when compared with its isolated use, being the combination of therapies important in the treatment of flaccidity.

\section{Keywords}

Sagging, Collagen, Radiofrequency, Electro-Stimulation

\section{Introduction}

Tissue flaccidity is considered to be an unsightly condition of the skin, characterized by fibroblasts decrease, which compromises collagen and elastin protein activity and is responsible for support and elasticity. Another form of flaccidity presentation is the one seen in muscles, and this is related to the decrease and little consistency in muscle tone. However, it is very common for both flaccidity types to appear simultaneously, worsening the appearance of the affected areas [1] [2] [3].

Collagen supplementation is among the treatment options. It is used to improve skin elasticity and firmness, justified by the decreased production of collagen in the body with advancing age, leading to a deficiency of this protein. The hydrolysed collagen is one of the available forms it is composed of amino acids that provide a high level of glycine and proline, two essential amino acids for the stability and regeneration of some tissues, with beneficial effects to the organism [4] [5].

Another therapeutic option is the use of radiofrequency ( $R F)$, a non-invasive therapy that allows thermal modification in the skin's connective tissue through dermal heating and vasodilation. The thermal action triggers a cascading inflammatory process and stimulates neocollagenesis, causing the thickening of the dermis. The association of these mechanisms improves the appearance of the skin, bringing good results to aesthetic problems [6].

Aiming at greater therapeutic efficiency, the association of therapies such as the use of electrostimulation, has been studied. Muscle tissue quality and quantity maintenance are among the objectives of this technique, as to resume the sensation of muscle tension, to gain or maintain muscle strength and to stimulate blood flow in the muscle. However, this technique must be combined with active muscle contraction, so that results are really achieved [7] [8].

Studies have shown that different combinations of exercises associated with electrostimulation were effective in the treatment of flaccidity, in addition to increasing muscle mass [9] [10]. Currently, no studies have been found that use the association of this therapy with other resources, such as radiofrequency and hydrolysed collagen for the treatment of skin and muscle laxity. Therefore, this study aimed at investigating the efficacy of the hydrolysed collagen associated with radiofrequency and electrostimulation protocols for the treatment of skin 
and muscle flaccidity in the abdominal and gluteal region (Firmez Method), establishing a protocol to be used by professionals in the field, in addition to demonstrating clinical and histological results.

\section{Materials and Methods}

This is a randomized clinical trial, duly approved by the Ethics Committee of Potiguar University (code: $3,671,537$ ) and carried out in compliance with the recommendations of the Consolidated Standards of Reporting Trials-CONSORT (Consort Transparent Reporting of Trials, 2010).

The group allocation sequence was followed according to a list generated by the Software Research Randomizer ${ }^{\mathrm{TM}}$ (Geoffrey C. Urbaniak and Scott Plous, Lancaster, EUA), and the volunteers were allocated according to the sequence in which they were evaluated.

\section{Participants}

Six volunteers with flaccidity in the abdominal and gluteal region and aged between 25 and 55 years old were evaluated. They were chosen through a nonprobabilistic method in the city of Natal/RN, Brazil. The inclusion criteria were: women aged between 25 and 55 years old, who presented abdominal and gluteal region flaccidity, with stretch marks in the abdominal region, with the ability to understand and preserved local sensitivity.

The exclusion criteria were applied to all participants who presented changes in sensitivity, who were pacemakers and automatic internal defibrillator users, in addition to the use of metal implants, haemophiliacs, and pregnant women. Participants who did not agree with the proposed procedures, presented sensitivity disorders during therapy, or did not adapt to the times and procedures. The procedures were discontinued in the presence of the aforementioned scenarios.

The volunteers were randomly divided through a random table into three groups: the hydrolysed collagen group (G-1), with two participants with an average age of $27.5 \pm 3.5$ years, the hydrolysed collagen group associated with radio frequency (G-2), with two participants with an average age of $45.0 \pm 14.1$ years and the hydrolysed collagen group associated with radio frequency and electrostimulation with active resisted exercises (G-3), with two participants with an average of $35.0 \pm 7.07$ years of age.

\section{Evaluation procedures}

The instruments to collect the data were a physical therapy questionnaire validated by Meyer cols. (2008) [11], in which the following topics were addressed: identification, anamnesis, physical examination, measurements, and tests such as weight, height, BMI, skin folding, and circumference measurements. Six abdominal punch surgeries were also performed for optical and microfocal microscopy analysis before and after the proposed treatment. At the end, the volunteers answered the questionnaires adapted from the analysis of patient satisfaction, Segot-chicq et al. [12] and the Global Aesthetic Improvement Scale-GAIS scale [13]. 
After the selection, the participants were informed about the procedures they would undergo. Those who agreed, signed the Free and Informed Consent Form. Then, they underwent an assessment of anthropometric, ultrasound and dynamometry measurements, which were performed in the pre-treatment, 30 , and 60 days after the beginning of the protocol, only the dynamometry was analysed before and after 60 days. An ultrasound device (Eco palm Wi-fi, $10 \mathrm{MHZ}$, China), a semi-professional camera (Canon, SX530 HS, Japan), a measuring tape (Fibre Glass Tape, China), an adipometer (Sanny, São Paulo, Brazil), and a scale (Accumed-Glicomed, Rio de Janeiro, Brazil) were used.

The equipment used in this study were the Narniah ${ }^{\mathrm{TM}}$ radio frequency from Medical $\operatorname{San}^{\mathrm{TM}}$ (Estrela, Brazil), the Fit 5.0 ${ }^{\mathrm{TM}}$ electro-stimulation device from Compex $^{\mathrm{TM}}$ (Carlsbad, EUA), hydrolysed collagen (Verisol ${ }^{\mathrm{TM}}$ and Peptiplus ${ }^{\mathrm{TM}}$, vitamins and minerals) and creams with active ingredients, Vividine Eutrófi$\mathrm{co}^{\mathrm{TM}}$, and Vividine Tissular ${ }^{\mathrm{TM}}$, from the Bothanica Mineral ${ }^{\mathrm{TM}}$ brand (São Paulo, Brazil).

The photos were taken with the volunteers in orthostatism with anterior and lateral (right and left) and posterior profiles, and the volunteer was asked to perform a shoulder flexion at $90^{\circ}$ during the photo session, using a tripod and a neutral coloured background for standardization.

Subsequently, the volunteers underwent an ultrasound examination performed in the infra and supra-umbilical region, with 4 different analysis areas: 2 areas located $4 \mathrm{~cm}$ above the umbilical scar and 2 areas located $4 \mathrm{~cm}$ below it. The distance between the analysed areas was approximately $5 \mathrm{~cm}$, with the volunteer positioned in the supine position. This method allowed the assess to the rectus abdominis muscle thickness before the procedures, and 30 and 60 days after the proposed treatment.

Fifteen days before the treatment started, the volunteers underwent a biopsy of pelvic abdominal streaks with a plastic surgeon. A fragment was removed from each volunteer in the lower abdominal region, with sizes between 5 and 6 $\mathrm{mm}$. The same technique was performed the end of the study. These samples were used for histological analysis of the inflammatory process, quantity and type of collagen and elastic fibres, blood vessels, and the presence of cell proliferation.

\section{Treatment protocol}

The hydrolysed collagen group (G-1) received the hydrolysed collagen powder and creams with active ingredients that were used in the abdominal and gluteal region daily, for two months. They also performed active resisted exercises for the abdomen and glutes (protocol: stretching, 4 exercises for the abdomen, 4 exercises for the buttocks and relaxation), performed 3 times a week in 24 sessions, totalling 60 minutes per session.

The hydrolysed collagen group associated with radiofrequency (G-2) also received treatment with hydrolysed collagen powder and creams with active ingredients with daily use for two months, being associated with radio frequency with application once a week in 8 sessions. The application was performed in the 
prone position for the gluteal region and in the supine position for the abdominal region, and the parameters used were $1200 \mathrm{kHz}, 120 \mathrm{w}, 40^{\circ} \mathrm{C}$, totalling 50 minutes per session. This group also performed active resisted exercises for the abdomen and glutes, keeping the same protocol, exercising 3 times a week in 24 sessions, totalling 60 minutes per session.

For G3, the daily intake of hydrolysed collagen powder was maintained for two months along with the use of creams with active ingredients associated with radiofrequency, with the same parameters, once a week in 8 sessions. The electrostimulation device, which has a biphasic current, symmetrical, $100 \%$ compensated and rectangular, with frequencies between $0-150 \mathrm{~Hz}$ was also applied. The protocols serve the purpose of sculpting the abdomen and tightening the buttocks. The active resistance exercise for the abdomen and buttocks, with contraction and relaxation time of approximately 10 seconds each, serve the same purpose. The same protocol was maintained, with the exercises performed 3 times a week distributed in 24 sessions, totalling 60 minutes per session.

Each volunteer answered a satisfaction and adverse reactions questionnaire after treatment conclusion. The reassessment was performed 30 and 60 days after the beginning of the study, with the repetition of all the mentioned tests and photos.

\section{Statistical analysis}

The analyses of statistical data were performed using the Package for the Social Sciences (SPSS) software version 22.0 for Windows (Armonk, EUA). First, the Kolmogorov Smirnov (K-S) test was performed to verify data normality. As we obtained a sample with normal distribution, we chose to perform the paired t-test for intragroup comparison (pre- and post-treatment) and the independent $\mathrm{t}$-test for intergroup data comparison (pre- and post-treatment). The qualitative data were described based on the pathologist's reports (descriptive analysis of histological images), in addition to the qualitative analysis of the photographic images and the quantitative responses to the applied questionnaires. Data collection and correlation were presented in tables and figures. Throughout the statistical analysis, a significance level of $95 \%$ was assigned, with $\mathrm{p}<0.05$.

\section{Results}

The anthropometric variables measured before (1st), 30 days (2nd), and 60 days (3rd) after the beginning of the study are described in Table 1. The data for weight, plicometry (right and left), and supra-umbilical perimetry did not present significant differences. However, there was a reduction in the G-3 infra umbilical perimeter measurement in comparison to the initial $(\mathrm{p}=0.03)$ and 30-day $(\mathrm{p}=$ $0.03)$ measuring. Furthermore, there was a significant difference with a reduction in the measurement when compared to groups G1 (initial $(p=0.03)$ and 30 days $(\mathrm{p}=0.04)$ ).

\section{Photographic analysis}

The photographs taken prior to the intervention were compared with those taken 30 and 60 days after the beginning of the protocol. Figures 1-3 show the 


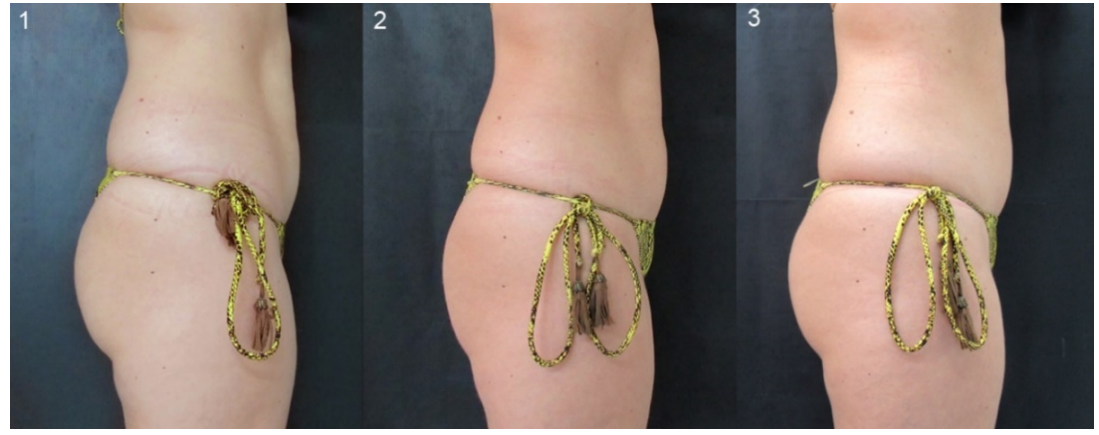

Figure 1. Hydrolysed collagen group (G-1): (1) initial; (2) 30 days; (3) 60 days.

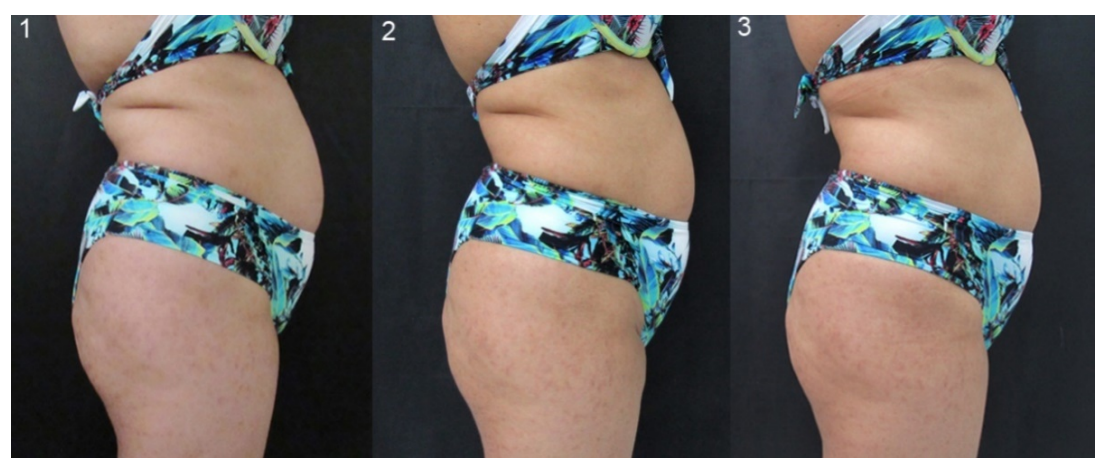

Figure 2. Hydrolysed collagen group associated with radio frequency (G-2): (1) initial; (2) 30 days; (3) 60 days.

Table 1. Volunteers' anthropometric data.

\begin{tabular}{|c|c|c|c|}
\hline & $G-1$ & $G-2$ & $G-3$ \\
\hline & Average \pm DP & Average \pm DP & Average $\pm \mathrm{DP}$ \\
\hline Weight $\left(1^{a}\right)$ & $76.5 \pm 17.4$ & $77.1 \pm 12.0$ & $76.3 \pm 0.42$ \\
\hline Weight $\left(2^{a}\right)$ & $78.3 \pm 19.2$ & $77.1 \pm 13.3$ & $76.2 \pm 1.13$ \\
\hline Weight (3a) & $80.0 \pm 20.4$ & $77.0 \pm 14.0$ & $76.3 \pm 0.63$ \\
\hline Plicometry $D\left(1^{a}\right)$ & $3.73 \pm 0.09$ & $4.53 \pm 0.18$ & $3.90 \pm 0.70$ \\
\hline Plicometry $D\left(2^{a}\right)$ & $4.17 \pm 0.98$ & $4.25 \pm 0.30$ & $3.72 \pm 0.35$ \\
\hline Plicometry D( $\left.3^{a}\right)$ & $3.90 \pm 0.80$ & $4.43 \pm 0.04$ & $3.50 \pm 0.80$ \\
\hline Plicometry E ( $\left.1^{\text {a }}\right)$ & $3.57 \pm 0.18$ & $4.35 \pm 0.16$ & $3.73 \pm 0.51$ \\
\hline Plicometry $E\left(2^{a}\right)$ & $4.13 \pm 1.03$ & $4.18 \pm 0.02$ & $3.67 \pm 0.32$ \\
\hline Plicometry E ( $\left.3^{a}\right)$ & $3.77 \pm 0.98$ & $4.37 \pm 0.18$ & $3.47 \pm 0.80$ \\
\hline Supra Perimetry $\left(1^{a}\right)$ & $93.7 \pm 21.5$ & $96.5 \pm 4.94$ & $87.0 \pm 5.65$ \\
\hline Supra Perimetry (2a) & $94.5 \pm 19.0$ & $95.0 \pm 2.82$ & $85.0 \pm 5.65$ \\
\hline Supra Perimetry ( $\left.3^{a}\right)$ & $92.0 \pm 19.7$ & $96.5 \pm 10.6$ & $84.5 \pm 6.36$ \\
\hline Infra Perimetry ( $\left.1^{a}\right)$ & $104.0 \pm 16.9$ & $105.5 \pm 4.94$ & $95.0 \pm 1.41$ \\
\hline Infra Perimetry $\left(2^{a}\right)$ & $105.5 \pm 16.2$ & $104.7 \pm 3.88$ & $94.0 \pm 1.41$ \\
\hline Infra Perimetry $\left(3^{a}\right)$ & $104.0 \pm 18.3$ & $104.5 \pm 4.94$ & $94.2 \pm 2.47$ \\
\hline
\end{tabular}




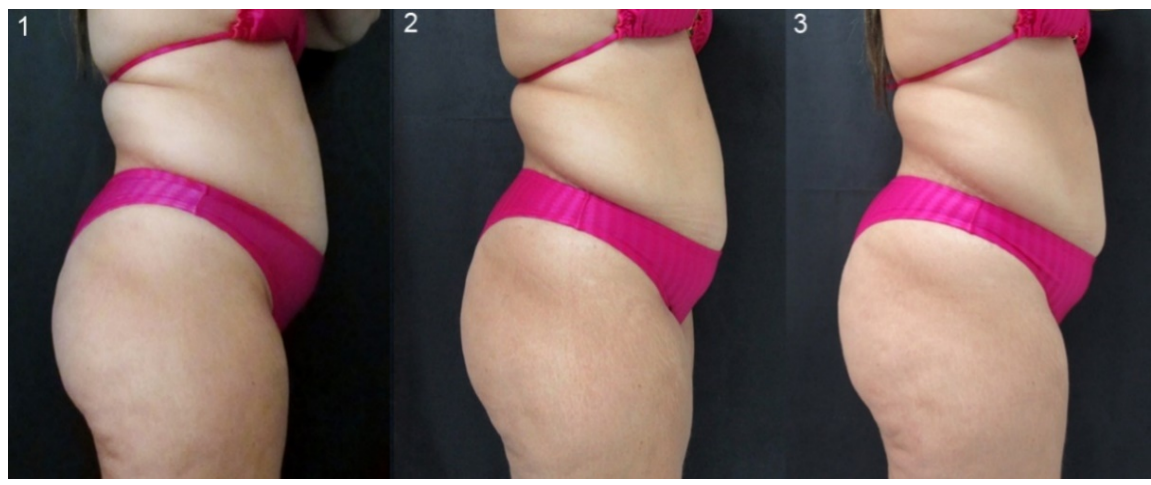

Figure 3. Hydrolysed collagen group associated with radio frequency and electrostimulation with active resisted exercise (G-3): (1) initial; (2) 30 days; (3) 60 days.

physical changes of the volunteers in each group. It is possible to observe an improvement in the musculature of the group that used hydrolysed collagen associated with radiofrequency and electrostimulation with active resisted exercise (G-3).

\section{Ultrasound Data}

The thickness of the rectus abdominis musculature was verified via ultrasound pre- and post-treatment at 30 and 60 days. Within G1, when compared to the initial assessment and after 60 days, showed an average increase of $0.23 \mathrm{~cm}$ for the upper right abdomen, and $0.18 \mathrm{~cm}$ for the left side. The lower abdomen region of the same group showed an increase of $0.23 \mathrm{~cm}$ for the direct side, and $0.14 \mathrm{~cm}$ for the left side.

Within G2, when compared to the initial assessment and after 60 days, the upper right abdomen showed an average increase of $0.17 \mathrm{~cm}$, and $0.07 \mathrm{~cm}$ for the left side. The lower abdomen region of the same group showed an increase of $0.16 \mathrm{~cm}$ for the direct side and $0.23 \mathrm{~cm}$ for the left side.

Within G3, when compared to the initial assessment and after 60 days, an average increase of $0.24 \mathrm{~cm}$ was identified for the right upper abdomen, and $0.33-\mathrm{cm}$ increase for the left side. The lower abdomen region of the same group showed an increase of $0.28 \mathrm{~cm}$ for the direct side and $0.26 \mathrm{~cm}$ for the left side. Thus, it is possible to show that there was a greater increase in muscle thickness in the group that used electrostimulation.

Despite the increase in abdominal musculature in all groups assessed by ultrasound, the statistical results did not show significant along the assessment periods within the groups ( $\mathrm{p}>0.05$ ) (Figure 4 and Figure 5).

\section{Strength assessment through dynamometry}

The strength gain evaluations of the abdominal and gluteal muscles were verified using a dynamometer device before and 60 days after treatment and the values were recorded in Table 2 . The strength assessment statistical results showed significant values in the intra-group analysis for abdominal muscles $(\mathrm{p}<0.05)$. In the same analysis, the right and left side gluteal musculature also showed significant values in all groups $(\mathrm{p}<0.05)$. 
TOP-LEFT

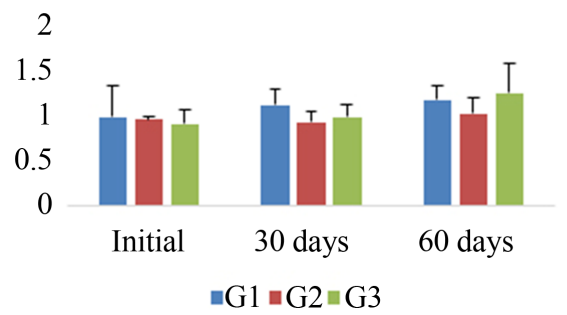

BOTTON-LEFT

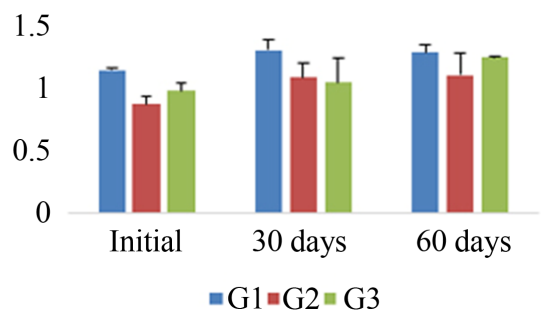

Figure 4. Analysis of upper and lower left ultrasound results for all groups at different times.

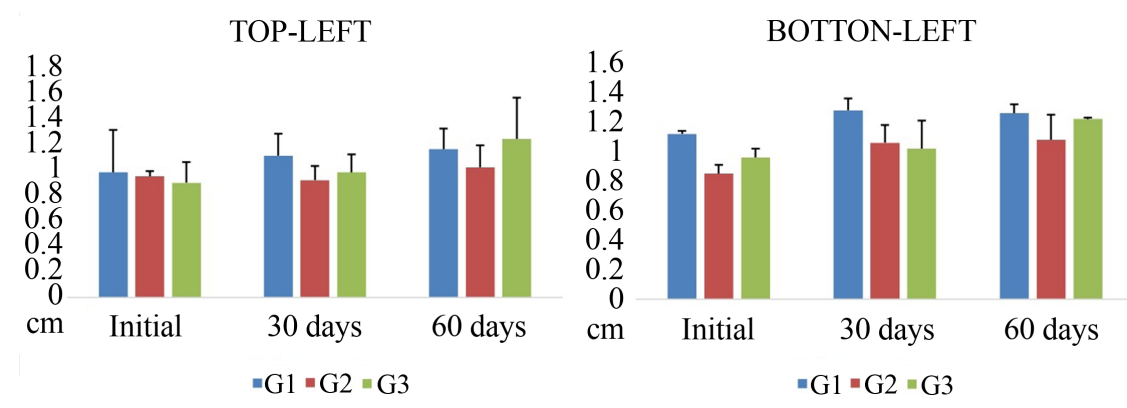

Figure 5. Analysis of upper and lower right ultrasound results for all groups at different times.

Table 2. Data of strength assessment with the dynamometer.

\begin{tabular}{cccc}
\hline & $G-1$ & $G-2$ & $G-3$ \\
\cline { 2 - 4 } & Average $\pm \mathrm{DP}$ & Average $\pm \mathrm{DP}$ & Average $\pm \mathrm{DP}$ \\
\hline Abdominal $\left(1^{\text {st }}\right)$ & $72.1 \pm 2.96$ & $29.4 \pm 2.40$ & $31.4 \pm 28.5$ \\
Abdominal $\left(2^{\text {nd }}\right)$ & $81.5 \pm 31.3$ & $44.0 \pm 4.54$ & $44.7 \pm 6.60$ \\
& $\mathrm{p}=\mathbf{0 . 0 4}$ & $\mathrm{p}=0.01$ & $\mathrm{p}=0.02$ \\
Gluteus $D\left(1^{\text {st }}\right)$ & $113.0 \pm 59.1$ & $30.9 \pm 0.49$ & $26.4 \pm 1.84$ \\
Gluteus $D\left(2^{\text {nd }}\right)$ & $130.2 \pm 50.5$ & $133.8 \pm 50.5$ & $41.8 \pm 0.51$ \\
Gluteus $E\left(1^{\text {st }}\right)$ & $\mathrm{p}=\mathbf{0 . 0 3}$ & $\mathrm{p}=0.04$ & $\mathrm{p}=0.03$ \\
Gluteus $E\left(2^{\text {nd }}\right)$ & $114.0 \pm 13.2$ & $29.8 \pm 0.71$ & $25.1 \pm 2.97$ \\
& $140.7 \pm 6.48$ & $120.9 \pm 52.6$ & $51.8 \pm 4.54$ \\
& $\mathrm{p}=\mathbf{0 . 0 4}$ & $\mathrm{p}=0.001$ & $\mathrm{p}=0.03$
\end{tabular}

In both evaluations between groups, the abdominal musculature showed significant results in the initial $(\mathrm{p}=0.01)$ and final $(0.01)$ moments. The same occurred with the gluteal muscles evaluation, with the initial right side $(\mathrm{p}=0.001)$ and final $(\mathrm{p}=0.001)$, and the left initial $(\mathrm{p}=0.02)$ and final $(0.04)$.

\section{Microscopic analysis}

Two tissue samples were taken before and at the end of the protocol. Histological analysis made it possible to observe the presence of collagen and fibrob- 
lasts and their quantification. The evaluation of the dermis of G1 volunteers observed in Figure 6(a) showed a normal amount of fibroblasts, and sparse and irregular collagen fibres. In contrast, within the volunteers from G2 and G3, regular dermis with thick fibres, a moderate amount of blood vessels, and inflammatory cells were identified, as shown in Figure 6(b) and Figure 6(c).

The amount of analysed fibroblasts and inflammatory cells showed significant differences ( $p<0.05$ ) when the group that used only collagen with exercises was compared to groups G2 and G3. When the differences between groups G-2 and G-3 were verified, these were not significant. In addition, the group that used electrostimulation showed a smaller amount of both cells. As of blood vessel quantification, similar data were found. G-2 and G-3 showed significant differences when compared to the control group; however, when compared to each other, they did not present significant values $(\mathrm{p}>0.05)$. It is worth mentioning that the group that used electrostimulation showed a greater amount of blood vessels in the analyses (Figure 7).

Microfocal histological analysis showed results regarding the type of collagen fibre and its quantification. Group G1 showed a predominance of type III collagen (green) (Figure 8), with $61 \%$ of type I collagen being quantified, while type III collagen presented 39\% (Figure 2(a)). For G2, an evident increase in type I collagen (orange) in relation to type III collagen (green) was identified, with $90 \%$ of the fibres corresponding to type I collagen, and only $10 \%$ to type III collagen (Figure 2(b)). G3 also showed an evident increase in type I collagen (orange) in relation to type III collagen (green), differing in the quantification, as $82 \%$ of the

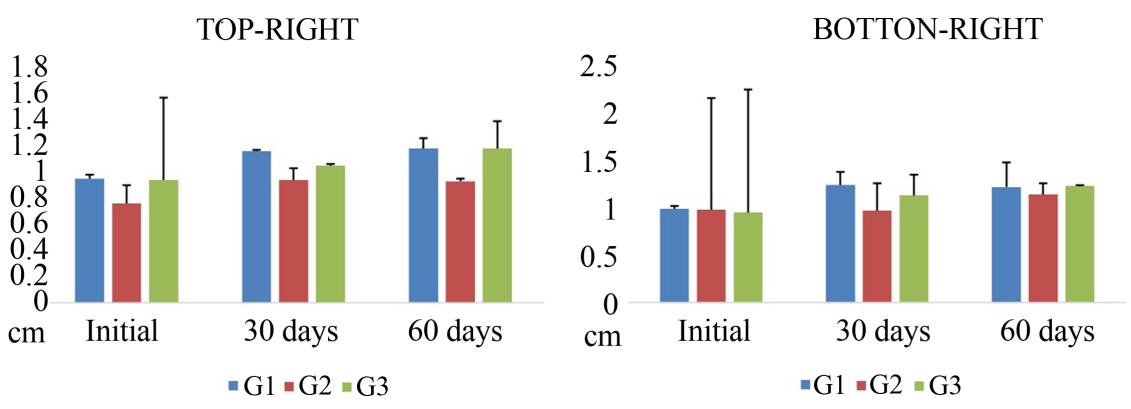

Figure 6. Histological analysis of the presence of collagen and fibroblasts and their quantification; (a) G1 blade; (b) G2 blade, and (c) G3 blade.
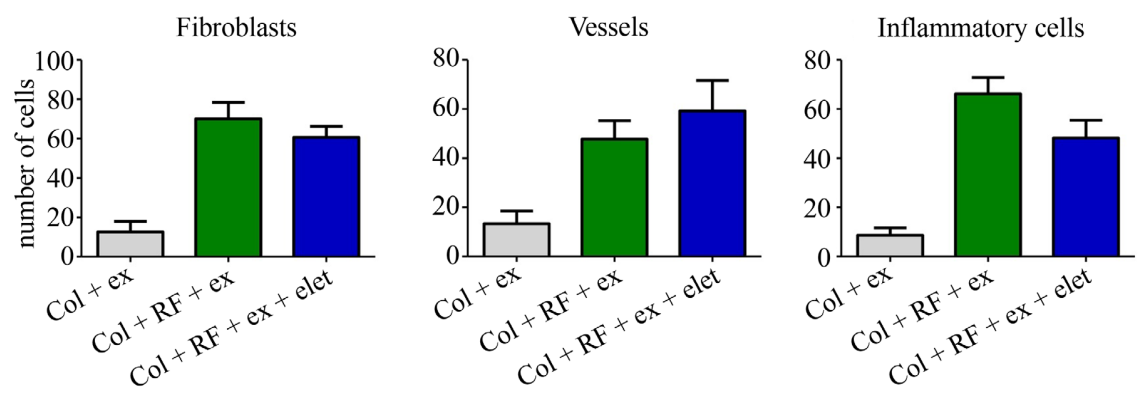

Figure 7. Comparison of fibroblasts, veins and inflammatory cells amounts found in each group. 

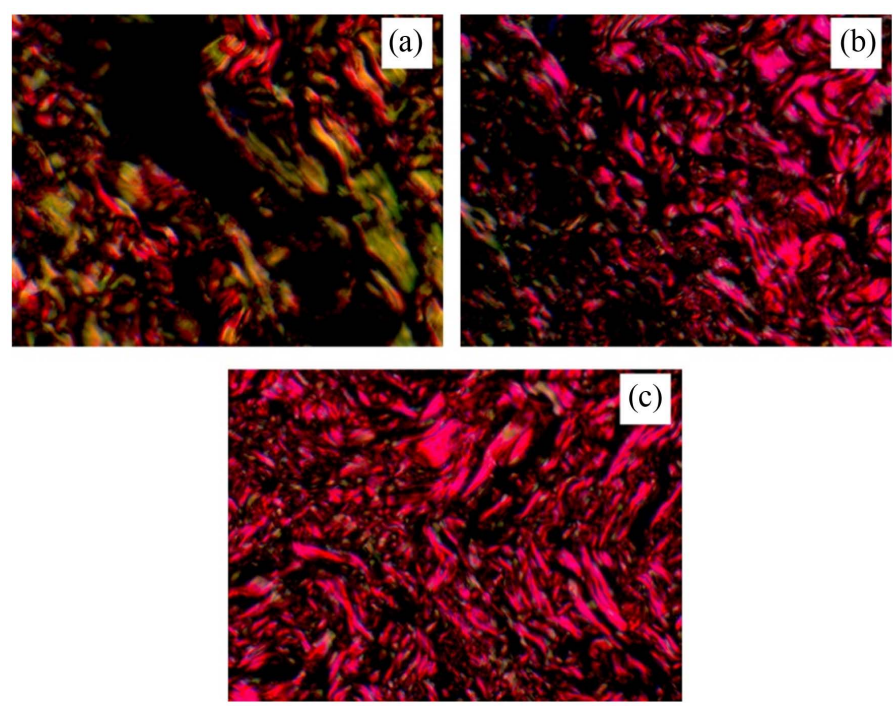

Figure 8. Microfocal histology for the type of collagen fibre and their quantification; (a) G1; (b) G2 and, (c) G3.

fibres corresponded to type I collagen, while $18 \%$ were correspondent to type III collagen (Figure 2(c)).

\section{Immunohistochemical analysis}

The Ki67 marker (cell proliferation marker) was identified, with G1 showing little cellular activity; G2 with the largest number of cells (fibroblasts, inflammatory and endothelial cells) in proliferation (Ki67+); G-3 with moderate amount of proliferating cells (fibroblasts, inflammatory, and endothelial cells) (Ki67+). In the statistical analysis, significant values were found when comparing G2 and G3 to the control group $(\mathrm{p}<0.05)$, and similarly, when comparing the groups that received the intervention with radiofrequency and electrostimulation $(\mathrm{p}<$ 0.05) (Figure 9).

The adverse reactions presented during the research were pain (50\% of G2), erythema (50\% of G3), hyperaemia (50\% of G2 and $50 \%$ of G3), in which one voluntary from G2 reported this reaction disappeared shortly after application, whereas the volunteer from G3 reported hyperaemia that lingered for approximately 1 hour. The topic "shocks during applications" was reported by only one volunteer from G3. For the item "marks on the skin", the G3 volunteer (50\%) reported they disappeared shortly after application. The topic "improved fluid retention" obtained $100 \%$ positive responses from all groups. There were no reports of paraesthesia, hypersensitivity, edema, bruising, burning, fat growth during applications, and none of the volunteers sought medical assistance (Figure 10).

When asked about the perception of looser clothing, 100\% of G1 and G2 reported the perception after the second week, $50 \%$ of G3 did not notice any change, and 50\% noticed it from the second week. Regarding the skin texture, $100 \%$ of G1 and G2 noticed "much firmer skin", while 50\% of G3 perceived "firmer skin" and 50\% "much firmer skin". 
Satisfaction with the results obtained with the protocol was $100 \%$ in all groups, and the treatment evaluation varied in group G1 between "excellent treatment" (50\%) and "very good treatment" (50\%), in G2 in "excellent treatment" (100\%) and in G3, the evaluation was between "excellent treatment" (50\%) and "very good treatment" (50\%) (Figure 11).

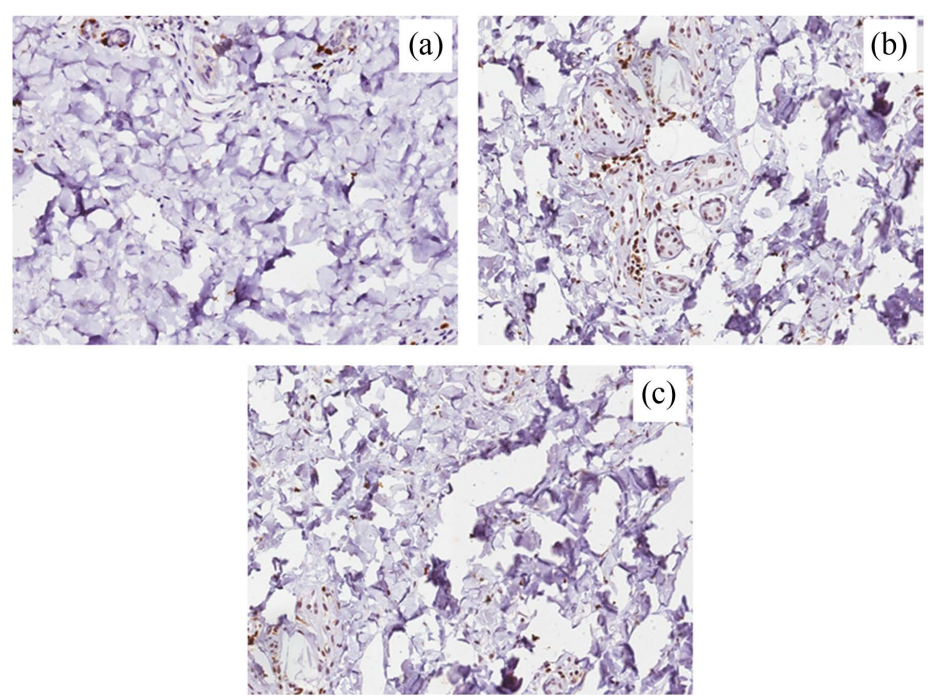

Figure 9. Histological analysis for Ki67 marker identification; (a) G1; (b) G2 and (c) G3.

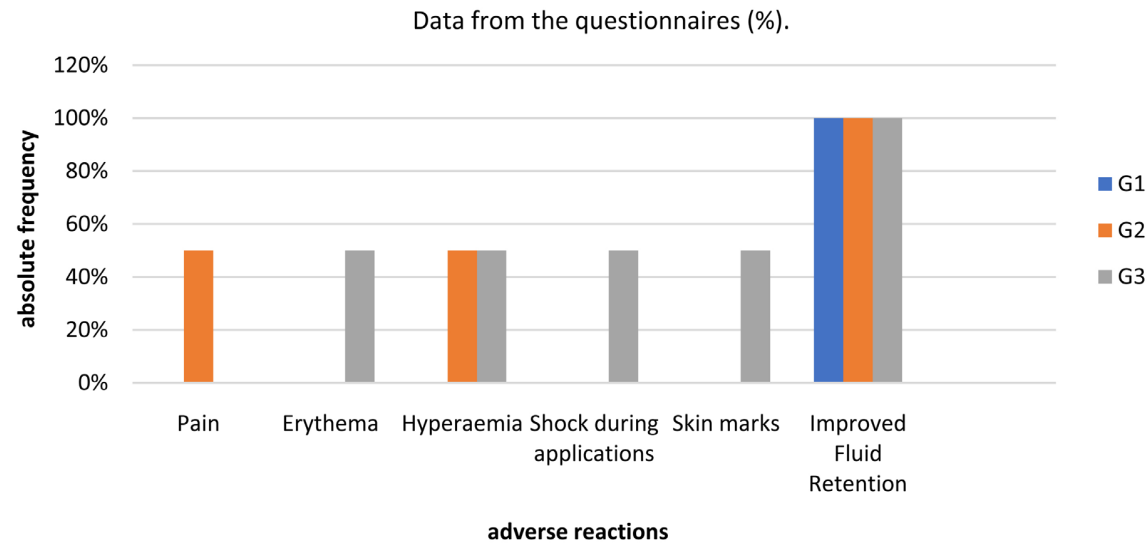

Figure 10. Data from the questionnaires (\%).

\section{TREATMENT ASSESSMENT}

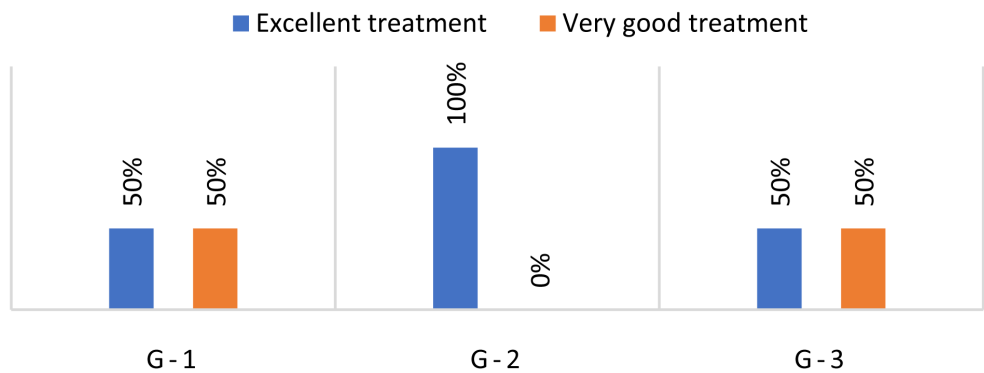

Figure 11. Comparison of treatment assessment results of the in each group. 


\section{Analysis of the questionnaires}

The global aesthetic improvement scale analysis showed that $50 \%$ of 1 reported being "much better" compared to the pre-treatment stage, while the other $50 \%$ reported "better". For G2, 50\% reported being "much better" and 50\% "much better", and G3 reported being "better" (50\%) and "much better" (50\%).

\section{Discussion}

The effectiveness of flaccidity treatments, whether related to tissue or muscle, are being frequently studied and different proposals for interventions have been presented. However, nowadays, there is the need to combine therapy protocols in order to obtain more efficient results for the treatment of aesthetic conditions [14].

Anthropometric measurements did not show significant body weight, plicometry and perimetry in the supra-umbilical region variations in any of the groups. These findings corroborate in part with the study by Porcariet et al. (2002) [15] who, when assessing the electrical stimulation response in 27 healthy individuals, did not find significant values for skinfold measurements, body weight, or body fat percentage after an 8-week training protocol.

Only G3's values of infra-umbilical perimetry showed a significant reduction in the intra-group analysis and when compared with the ones from G1, which may be related to the use of electrostimulation; however, no study showing this association was found in the currently available literature.

The ultrasound data showed that there was a progressive increase in the thickness of the abdominal muscles in all groups studied, however, without significant values. Despite this, the strength assessment showed significant values in the intra-group analysis for the abdominal and gluteal muscles $(\mathrm{p}<0.05)$ and equally in the assessment between the groups $(\mathrm{p}<0.05)$. Obtaining these results demonstrates that there is some improvement in the musculature regarding thickness and strength in individuals who performed the active exercises. However, no great differences were found within the group that used the associated electrostimulation, even though this was responsible for triggering visible muscle contractions due to the activation of intramuscular nerve branches [16].

According to Gondinet et al. (2005) [17], the use of electrostimulation promotes significant changes in muscle mass and architecture after 4 to 8 weeks of the training program. In their study involving 20 individuals who received 32 Neuromuscular Electrical Stimulation (NMES) sessions with isometric exercises for 8 weeks, it was observed that neural adaptations are responsible for the largest proportion of initial strength increase, while muscle adaptations participate in the additional increase in strength.

Nevertheless, the study by Avila, Brasileiro and Salvini (2008) [18], when analysing the effects of electrostimulation associated with an isokinetic training programme for 4 weeks, demonstrated that the association between electrostimulation and exercise did not improve the strength gains and neuromuscular 
deprivations of the voluntary strength training itself. Thus, it is possible to notice that the literature is still quite controversial as to the results provided by electrostimulation.

The histological analysis identified a regular dermis with thick fibres, and a moderate amount of blood vessels and inflammatory cells in both groups that received radiofrequency. This is due to thermal injury that triggers a cascade of inflammatory events, including fibroblast proliferation and positive regulation of collagen expression. It has been reported that after a few weeks of this therapy, there is an increase in collagen deposition that takes a horizontal orientation parallel to the plane of the epidermis and in some cases dermal thickening is reported [19].

It is important to mention that in the analysed sample, the group that used radiofrequency and electro-stimulation associated with exercise had a lower amount of fibroblasts and inflammatory cells when compared to the group that underwent radiofrequency sessions and exercises only, leading to the hypothesis that the use of electrostimulation may have presented itself as an inhibiting factor. However, no study that could correlate this finding was found in the current literature. Due to the small sample, data analysis must be performed with caution.

For the group that received electrostimulation, greater amounts of blood vessels were found in the histological analysis when compared to the other groups, so, in addition to the radiofrequency, the use of the electrostimulation device may have induced the greater appearance of blood vessels in this group, as it is acknowledged that its use can increase the blood flow of the stimulated region. The study by Miller, Gruben, and Morgan (2000) [20] demonstrated that contractions performed with electrostimulation produced vasodilation in the muscle and skin, maintained above baseline levels for 15 seconds after the exercise, which is a longer time when compared to voluntary contraction. Thus, the region that used electrical stimulation remained with increased blood flow for a longer time.

The dermal extracellular matrix provides strength and resistance to the skin, and it is formed mainly by type I collagen; however, the advancing age leads to a decrease in the synthesis of this type of collagen and evidences type-III collagen, reducing the mechanical and binding forces of the skin. In addition, some changes in the morphological and biomechanical properties lead to the appearance of flaccidity [21] [22]. For the microfocal histological analysis, G2 and G3 presented higher values of type-I collagen in relation to G1, which also showed an increase in this type of collagen; however, less significantly, this can be justified due to the intake of collagen by all groups.

The study by Schwartz and Park (2012) [23] observed the effect of a dietary supplement that contained hydrolysed type-II collagen, low molecular weighthyaluronic acid and chondroitin sulphate in 26 women with facial aging. The results showed that the intake increased the collagen content in the dermis, be- 
ing significant until the sixth evaluated week, but not up to the $12^{\text {th }}$ week. Thus, supplementation modifies the metabolic balance between type I and/or type III-collagen biosynthesis by dermal fibroblasts and their degradation by matrix metalloproteinases, concluding that the ingestion of hydrolysed collagen affects the physiological processes associated with aging.

The radiofrequency has been a commonly used treatment when it is intended to improve tissue flaccidity, as it acts by inducing a thermal damage that stimulates changes in the formation of collagen and in the production of neocolagenesis. The presence of type-I collagen on the treated side indicates an improvement in skin firmness and elasticity, which is confirmed in the study by Zelickson et al. (2004) [24], who, through histological analysis, demonstrated changes in the areas of collagen fibres, with an increase in the diameter and amount of type-I collagen after 8 weeks of treatment with radiofrequency. Yokoyama et al. (2014) [25] evaluated skin samples from five volunteers, collected before treatment and 1 and 3 months after treatment using monopolar radio frequency. The results obtained indicate that collagen types I and III increased three-dimensionally and uniformly.

In the study by Meyer et al. (2017) [26], when analysing the effects of radiofrequency associated or not with hydrolysed collagen in the skin tissue in 20 Wistar rats, it was observed that type-I collagen in the groups that used only hydrolysed collagen, or only radiofrequency, or the association between these two therapies, was significantly higher than in the control group. The sample that received the association of the procedures presented higher amounts of type-I collagen. In addition, the collagen fibres showed the thickest and regular distribution. It was concluded that the use of radiofrequency, alone or associated with hydrolysed collagen, increases and improves neocolagenesis, neoangiogenesis and dermis thickness.

Another analysed marker was the significant increase in the number of fibroblasts and inflammatory cells positive for Ki67, with a greater amount being found inG2. However, the greater presence in only one of the groups that used the radiofrequency was not clear. It is known that in treated skins, the expression of Ki67 in fibroblast nuclei, connective tissue cells, and inflammatory cells indicate a greater proliferation of fibroblasts in the region, making it more resistant and promoting better tissue quality [27].

Regarding overall satisfaction with the treatment outcome, all volunteers indicated it was positive, as well as the concepts most cited by them are "excellent treatment" and "very good treatment". In the overall aesthetic improvement, all volunteers reported being better after treatment. There were reports of adverse reactions for treatment between G2 and G3, with pain, erythema, hyperaemia, shock during sessions and skin marks being the most frequent. The positive points highlighted by the volunteers were the improved fluid retention among all groups, the perception of looser clothing and improved skin texture, it was reported that the skin was much firmer. Thus, it is evident that the use of com- 
bined therapies is essential in the achievement of better results and good receptivity by patients [14].

When analysing the data presented by the group that received the collagen and the exercises only (G1), it is possible to notice that, in addition to having moderately satisfactory results in the analysed variables, they also obtained positive results in the evaluated questionnaires, being so, even in the case of a control group, there was an influence on their final, whether due to use of the proposed therapies, the effects of the expectations towards the treatment, or the care and attention given to the participants, which were reported by other authors, regardless of significant results in the variables analyzed [28] [29].

\section{Conclusion}

The Firmez ${ }^{\mathrm{TM}}$ method was effective in improving tissue and muscle flaccidity, with positive results in the analysed variables and histological presentation, with improved collagen in the studied region. In addition, there was high satisfaction of the volunteers. However, it was not possible to determine whether the group that used electrostimulation obtained better results than the others. Therefore, it is necessary to carry out additional studies that count on larger samples and replicate this methodology, so that the results found in this study can be further expanded.

\section{Conflicts of Interest}

The authors declare no conflict of interest.

\section{References}

[1] Baumann, L., Bernstein, E.F., Weiss, A.S., Bates, D., Humphrey, S., Silberberg, M. and Daniels, R. (2021) Clinical Relevance of Elastin in the Structure and Function of Skin. Aesthetic Surgery Journal Open Forum, 3, No. 3. https://doi.org/10.1093/asjof/ojab019

[2] Borges, F.S. (2006) Dermato-Funcional: Modalidades terapêuticas nas disfunções estéticas. Phorte, São Paulo, 6.

[3] Bergfeld, W.F. (1999) A Lifetime of Healthy Skin: Implications for Women. International Journal of Fertility and Women's Medicine, 44, 83-95.

[4] Prestes, R.C., Golunski, S.M., Toniazzo, G., Kempka, A.P. and DiLuccio, M. (2013) Caracterização da fibra de colágeno, gelatina e colágeno hidrolisado. Revista Brasileira de Produtos Agroindustriais, 15, 375-382. https://doi.org/10.15871/1517-8595/rbpa.v15n4p375-382

[5] Silva, T.F. and Penna, A.L.B. (2012) Chemical Characteristics and Functional Properties of Collagen. Revista do Instituto Adolfo Lutz, 71, 530-539.

[6] Bravo, B.S., Issa, M.C., de Souza Muniz, R.L. and Torrado, C.M. (2013) Tratamento da lipodistrofiaginoide com radiofrequência unipolar: Avaliação clínica, laboratorial e ultrassonográfica. Surgical \& Cosmetic Dermatology, 5, 138-144.

[7] Briel, A.F., Pinheiro, M.F. and Lopes, L.G. (2003) Influência da corrente russa no ganho de força e trofismo muscular dos flexores no antebraço não dominante. Arquivos de Ciências da Saúde da UNIPAR, 7, 205-210. 
[8] Camargo, L.C., Minamoto, V.B., de Noronha, M.A., dos Santos Castro, C.E. and de Fátima Salvini, T. (1998) A estimulação elétrica neuromuscular do tibial anterior não altera a morfologia dos músculos sóleo (antagonista) e extensor digital longo (sinergista) do rato. Fisioterapia e Pesquisa, 5, 120-126.

[9] Monção, E.G., de Medeiros Moura, W.E., Cardoso, S.B., de Campos, J.C., Monteiro, A.N. and da Silva Franca, J. (2013) O uso da eletroestimulacao muscular com corrente de media frequência associada ao exercicio resistido no musculo gluteomaximo: Estudo de caso. Acta Biomedica Brasiliensia, 4, 81-89.

[10] Lima, E.P. and Rodrigues, G.B. (2012) A estimulação russa no fortalecimento da musculatura abdominal. Arquivos Brasileiros de Cirurgia Digestiva, 25, 125-128. https://doi.org/10.1590/S0102-67202012000200013

[11] Mendonça, A.G., Rodrigues, R.D., Corradi, D.P., Cruz, L.B., Meyer, P.F., Antunes, M.D. and Agne, J.E. (2008) Protocolo de avaliação fisioterapêutica em adiposidade localizada. Fisioterapia Brasil, Suplemento Especial, 26-31.

[12] Segot-Chicq, E., Compan-Zaouati, D., Wolkenstein, P., Consoli, S., Rodary, C., Delvigne, V., Guillou, V. and Poli, F. (2007) Development and Validation of a Questionnaire to Evaluate How a Cosmetic Product for Oily Skin Is Able to Improve WellBeing in Women. Journal of the European Academy of Dermatology and Venereology, 21, 1181-1186. https://doi.org/10.1111/j.1468-3083.2007.02193.x

[13] Narins, R.S., Brandt, F., Leyden, J., Lorenc, Z.P., Rubin, M. and Smith, S. (2003) A Randomized, Double-Blind, Multicenter Comparison of the Efficacy and Tolerability of Restylane versus Zyplast for the Correction of Nasolabial Folds. Dermatologic Surgery, 29, 588-595. https://doi.org/10.1097/00042728-200306000-00006

[14] Fabi, S., Pavicic, T., Braz, A., Green, J.B. and Seo, K. (2017) Combined Aesthetic Interventions for Prevention of Facial Ageing, and Restoration and Beautification of Face and Body. Clinical, Cosmetic and Investigational Dermatology, 10, 423-429. https://doi.org/10.2147/CCID.S144282

[15] Porcari, J.P., Mclean, K.P., Foster, C., Kernozek, T., Crenshaw, B. and Swenson, C. (2002) Effects of Electrical Muscle Stimulation on Body Composition, Muscle Strength, and Physical Appearance. The Journal of Strength \& Conditioning Research, 16, 165-172. https://doi.org/10.1519/00124278-200205000-00001

[16] Maffiuletti, N.A. (2010) Physiological and Methodological Considerations for the Use of Neuromuscular Electrical Stimulation. European Journal of Applied Physiology, 110, 223-234. https://doi.org/10.1007/s00421-010-1502-y

[17] Gondin, J., Guette, M., Ballay, Y. and Martin, A. (2005) Electromyostimulation Training Effects on Neural Drive and Muscle Architecture. Medicine \& Science in Sports \& Exercise, 37, 1291-129. https://doi.org/10.1249/01.mss.0000175090.49048.41

[18] Avila, M.A., Brasileiro, J.S. and Salvini, T.F. (2008) Electrical Stimulation and Isokinetic Training: Effects on Strength and Neuromuscular Properties of Healthy Young Adults. Brazilian Journal of Physical Therapy, 12, 435-440. https://doi.org/10.1590/S1413-35552008005000006

[19] Kaplan, H. and Gat, A. (2009) Clinical and Histopathological Results Following TriPollar $^{\mathrm{TN}}$ Radiofrequency Skin Treatments. Journal of Cosmetic and Laser Therapy, 11, 78-84. https://doi.org/10.1080/14764170902846227

[20] Miller, B.F., Gruben, K.G. and Morgan, B.J. (2000) Circulatory Responses to Voluntary and Electrically Induced Muscle Contractions in Humans. Physical Therapy, 80, $53-$ 60. https://doi.org/10.1093/ptj/80.1.53

[21] Paasch, U., Bodendorf, M.O., Grunewald, S. and Simon, J.C. (2009) Skin Rejuvenation by Radiofrequency Therapy: Methods, Effects and Risks. JDDG: Journal der Deutschen 
Dermatologischen Gesellschaft, 7, 196-203.

https://doi.org/10.1111/j.1610-0387.2008.06780.x

[22] Quan, T., Wang, F., Shao, Y., Rittié, L., Xia, W., Orringer, J.S., Voorhees, J.J. and Fisher GJ. (2013) Enhancing Structural Support of the Dermal Microenvironment Activates Fibroblasts, Endothelial Cells, and Keratinocytes in Aged Human Skin in Vivo. Journal of Investigative Dermatology, 133, 658-667. https://doi.org/10.1038/jid.2012.364

[23] Schwartz, S.R. and, Park. J. (2012) Ingestion of BioCell Collagen ${ }^{\mathrm{Tm}}$, a Novel Hydrolyzed Chicken Sternal Cartilage Extract; Enhanced Blood Microcirculation and Reduced Facial Aging Signs. Clinical Interventions in Aging, 7, 267. https://doi.org/10.2147/CIA.S32836

[24] Zelickson, B.D., Kist, D., Bernstein, E., Brown, D.B., Ksenzenko, S., Burns, J., Kilmer, S., Mehregan, D. and Pope, K. (2004) Histological and Ultrastructural Evaluation of the Effects of a Radiofrequency-Based Nonablative Dermal Remodeling Device: A Pilot Study. Archives of Dermatology, 140, 204-209.

https://doi.org/10.1001/archderm.140.2.204

[25] Yokoyama, Y., Akita, H., Hasegawa, S., Negishi, K., Akamatsu, H. and Matsunaga, K. (2014) Histologic Study of Collagen and Stem Cells after Radiofrequency Treatment for Aging Skin. Dermatologic Surgery, 40, 390-397.

https://doi.org/10.1111/dsu.12443

[26] Meyer, P.F., de Oliveira, P., Silva, F.K., da Costa, A.C., Pereira, C.R., Casenave, S., Silva, R.M., Araújo-Neto, L.G., Santos-Filho, S.D., Aizamaque, E. and Araújo, H.G. (2017) Radiofrequency Treatment Induces Fibroblast Growth Factor 2 Expression and Subsequently Promotes Neocollagenesis and Neoangiogenesis in the Skin Tissue. Lasers in Medical Science, 32, 1727-1736. https://doi.org/10.1007/s10103-017-2238-2

[27] Gasparri, F., Mariani, M., Sola, F. and Galvani, A. (2004) Quantification of the Proliferation Index of Human Dermal Fibroblast Cultures with the ArrayScan ${ }^{\mathrm{Tm}}$ HighContent Screening Reader. Journal of Biomolecular Screening, 9, 232-243. https://doi.org/10.1177/1087057103262836

[28] Teixeira, M.Z. (2009) Bases psiconeurofisiológicas do fenômeno placebo-nocebo: Evidências científicas que valorizam a humanização da relação médico-paciente. Revista da Associação Médica Brasileira, 55, 13-18. https://doi.org/10.1590/S0104-42302009000100008

[29] Mlosek, R.K., Woźniak, W., Malinowska, S., Lewandowski, M. and Nowicki, A. (2012) The Effectiveness of Anticellulite Treatment Using Tripolar Radiofrequency Monitored by Classic and High-Frequency Ultrasound. Journal of the European Academy of Dermatology and Venereology, 26, 696-703. https://doi.org/10.1111/j.1468-3083.2011.04148.x 